\title{
The physical and geochemical properties of gas-bearing sediments in the Yeosu Bay and Jinhae Bay, the South Sea of Korea
}

\author{
Gwang-Soo Lee ${ }^{1}$, Sora Kim ${ }^{1}$ \\ ${ }^{1}$ Petroleum \& Marine Research Division, Korea Institute of Geoscience and Mineral Resources (KIGAM), Daejeon, South \\ Korea
}

\begin{abstract}
Analysis of high-resolution seismic profiles and sediment core was conducted to investigate the physical and geochemical property of gas-bearing sediments in Yeosu Bay and Jinhae Bay, the South Sea of Korea. Acoustic anomalies associated with shallow gas are widely distributed in the bay and can be divided into two types. Type I has a very strong and shallow top reflection that is parallel to the seafloor, with acoustic blanking or turbidity of inner stratigraphy. Type II is characterized by sharp top reflection along the seafloor. Physical property and textures of sediment core that penetrate the gasbearing zones, show no significant downcore variation regardless existence of gas bubbles. However, velocity dramatically decreases from average $1497 \mathrm{~m} / \mathrm{s}$ to $911-1404 \mathrm{~m} / \mathrm{s}$ at the gas-bearing zone. $\mathrm{C} / \mathrm{N}$ ratios (8.3-12.0) of the organic matter in the cored sediments in the Yeosu Bay suggest mixed marine and terrestrial sources. The content of organic matter from ignition loss and $\mathrm{C} / \mathrm{N}$ ratios of cored sediments in the Jinhae Bay varied between 7.8 10.4\% and 6.8 8.2, respectively. The $\mathrm{C} / \mathrm{N}$ ratios imply that the sediments of Jinhae Bay are also comprised of mixtures derived from biogenic and terrigenous organic matter. It is concluded that physical and geochemical property of gas-bearing sediments in the Yeosu Bay and Jinhae Bay are closely related to the sedimentary environment, the content of organic matter, water depth, and sedimentary strata.
\end{abstract}

